\title{
NOMES. NOME. N.O.M.E. Considerações sobre o nome e a transmissão no seminário O sinthoma
}

\section{Glaucia Nagem}

\author{
Nome e transmissão: \\ Um não é o outro. \\ Um não é sem o outro. \\ Um não se sobrepõe ao outro.
}

Um.

Outro.

(A autora)

Nome e transmissão podem ser a designação para duas formigas na banda de Mœbius. E as duas poderiam cantarolar o apólogo deste texto, produzido a partir da orientação das discussões no Espaço Escola do FCL-SP ${ }^{1}$. Nome, nomear, transmitir são questões que acompanham Lacan desde cedo em suas voltas. O que ele nos diz sobre isso no Seminário 23? O que ele aprendeu com Joyce a esse respeito?

Bousseyroux nos diz a respeito do RSI que:

[...] com o enodamento RSI o objeto $a$ mudou de estatuto: ele não consiste mais como superfície, ele ex-siste, como ponto de coinçagem do nó. O fato é também que o sintoma toma o passo sobre o fantasma para dar conta do fim da análise, a separação final se definindo mais pela identificação ao sintoma. O fato é ainda que o inconsciente muda também de estatuto: a princípio igual ao sintoma, Lacan terminará por apresentá-lo, em 10 de outubro 1978 em Saint-Anne, como real, rodela do real à qual a rodela do simbólico impõe a lei (BOUSSEYROUX, 2001, p. 255)².

\footnotetext{
1 Espaço Escola é uma reunião mensal onde os temas ligados à Escola e suas instâncias são discutidos com os delegados que são membros de Escola.

2 Tradução livre de: "avec le noage R.S.I. I'objet a change de statut: il ne consiste plus comme surface, il ex-siste, como point de coincement du noeud. Le fait est aussi que le symptôme prend le pas sur le fantasme pour rendre compte de la fin de l'analyse, la separation finale se définssant davantage par
} 
E ainda, se acompanharmos Soler em seu livro Lacan Leitor de Joyce, a autora ressalta que sintoma e sinthoma soam do mesmo modo, afirmando que, com essas palavras, Lacan joga com o equívoco do som e da grafia (SOLER, 2015, p. 9). Joyce também o faz em suas obras, de Ulysses até Finnegans Wake. De forma que acompanhamos a construção, em 1972, desse lugar privilegiado do som, juntamente com a aposta de que os registros se enodam, desenodam e reenodam de modos variados.

Para acompanharmos o Seminário 23, é imprescindível ler e reler as construções joyceanas. Nelas, a questão dos nomes é muito importante, sendo largamente explorada pelo autor. Ressaltarei o trabalho feito por ele em um pré-escrito, ou ur-livro, que foi utilizado na construção de Finnegans Wake. Trata-se de Finns Hotel, em que Joyce, de acordo com alguns comentadores, está fomentando e se abastecendo para a criação do Finnegans.

Em sua introdução ao livro, Danis Rose comenta: "Os ur-livros são como enzimas, que lhe catalisam a criatividade” (ROSE, 2014, p. 17), e ainda nos indica que, de todos os contos, o principal é aquele que conta como o pai ganhou o nome de Earwicker. Intitulado "Homem comum em fim", neste conto o som é convocado diversas vezes nas construções de palavras e principalmente dos nomes. Ouçamos Joyce:

No que concerne à gênese do agnome de Harold ou Humphrey Coxon e descartando-se de uma vez por todas as teorias de fontes mais antigas que o ligavam a ancestrais pivotais tais que os Glue, os Gravy e os Earwicker de Sidham em Hundred of Manhood ou o proclamavam descendentes de vikings [...].

A sua majestade, que era, ou fingia ser, perceptivelmente de vista longa desde a mais tenra infância e estava querendo inquirir o que houvera causado que se escavasse a estrada tanto assim, pedindo alternativamente, que se lho dissera se acaso não eram paternoste e silverdoctors iscas mais na moda para armadilhas de lagostas, o franconesto Haromphreyld respondeu em tons seguros mui similarmente com destemido cenho: Ná, samaguestá, queu só tarra pegano sas porra sas tisurinhas queis chama irwik.[...].

- Santossada, como fumaria audivelmente nosso rubro irmão de Chuvenbaldes se soubera que temos por bailio um canceleiro que reveza de cão seleiro além ainda de earwikar! (JOYCE, 2014, pp. 107-108).

I'identification au symtôme. Le fait est encore que l'inconscient change aussi de statut: d'abord égalé au simbolique Lacan finira par le présenter, le 10 octubre 1978 à Sainte-Anne, comme réel, rond du réel auquel de rond du symbolique 'impose la loi'". 
Vale a pena ler o texto inteiro, mas trago apenas alguns recortes para que se tenha a escuta de que o nome desse personagem desliza e desloca os sentidos pelos sons. É um texto extremamente sonoro e claramente ligado ao tratamento dado por Joyce ao texto de Finnegans Wake. Nesses trechos que assinalo podemos observar como o som do nome desse pai desliza: Earwicker - ear (orelha) - wicker (vime) - wicked: malvado. Um nome, vários sons, sentidos variados.

Essa multiplicidade oferecida pela obra de Joyce a Lacan está ligada ao N.O.M.E. Explico-me: pelo que acompanhamos na obra lacaniana desde seus primeiros seminários a questão do fim de análise está em jogo. Em suas construções nos anos 70 , vemos no final de uma análise algo do nome se multiplicar para além do sentido cristalizado do sintoma do início dessa análise. Se o sintoma que nos chega é um embaraçado de significações: "Sou isso para o Outro", no fim temos a redução desses sentidos àquilo que poderia ser o puro som que se lança ao $a b$-sens. Um passo de sentido que tem a seu favor o que Joyce nos apresenta: os sons.

\section{Nomes - Nome - N.O.M.E.}

Mas sabemos que essa não é uma passagem direta.O sujeito é falado com os vários nomes que se associam a ele como atributos,para noutro passo fazer seu nome próprio. Ele passa dos nomes ao nome próprio.

Esse nome próprio por si obtura o furo, posto que pode cristalizar-se como significação. No entanto, fazer-se um nome que não sejam os atributos que lhes são oferecidos em seu nascimento não é o fim de uma análise, mas um tempo. Dos nomes-atributos do início: "sou isso para o outro", passando pela questão "o que sou para o outro", o nome próprio entra no jogo pela obturação que ele faz nessa dialética. Acompanhamos como o ser e o pensar se dissociam nas construções de Lacan, e ainda, que a colagem deles traz consequências sérias nos laços do falasser.

A preocupação de Lacan, desde o início, estava em perguntar o que é uma análise e qual o seu fim. "Seu fim" no sentido amplo que pode ter este termo, qual seja, o término e a direção. Para chegar a isso ele faz várias voltas em seus seminários: desde a mudança de posição do espelho plano quando trabalha seus espelhos, passando pelos cortes sobre as superfícies topológicas, até chegar, no Seminário 23, a um novo passo.

Soler (2015) aponta que o inconsciente em Lacan vai do inconsciente romance ao real da letra. Isso não é sem consequências para a questão do nome e do final da análise. Todo o romance que encontramos no Seminário 12 sobre o nome-sintoma-fantasma de "POOR (d) J' e-LI"mesmo que escrito com sons e letras, está baseado em um inconsciente escorado na história papaimamãe. Temos com isso uma proximidade com os nomesintomas freudianos, cuja leitura carregava uma gama de histórias. 
Com sua literatura, Joyce oferece a Lacan um diagnóstico original. Nos diz Soler que “'Joyce, o sintoma' não é uma interpretação da obra joyceana, mas um diagnóstico original do que Lacan nomeia, como o faz o próprio Joyce, 'o artífice'. O diagnóstico de uma unicidade, o contrário de um tipo, portanto. Diagnóstico de uma 'diferença absoluta', o único digno de um psicanalista" (SOLER, 2015, p. 17). Joyce, o sintoma, não nomeia uma patologia, mas uma solução.

Joyce se nomeia na medida em que lança seu nome para além do nome do pai. Ele vai além, forja algo único, um nome com o qual os universitários se ocupariam por pelo menos um século!

Lacan inicia o Seminário 23 com a questão do nome e da nomeação: "Deus não nomeia as bactérias!” (LACAN, 1975-76/2007). Ora, ainda assim elas estão lá. A referência ao livro do Gênesis não é à toa; neste livro vemos uma sequência que começa na criação, passa pela nomeação e termina na reduplicação dessa nomeação.

A invenção é mínima: o Céu, a Terra, a Luz. E a partir desse mínimo a criação passa a ser nomeada ${ }^{3}$. Adão, o Falasser, nomeia os animais, e em seu falatório "reduplica a criação divina" (BOUSSERAUX, 2001, p. 14). A tal serpente entra empostada para furar essa história do falasser, sendo auxiliada por nada menos que uma mulher.

Já de saída, Lacan nos apresenta a questão da criação e do nomear. Um e outro não se misturam na criação disso que não precisa ter nome para existir, mas que precisa se reduplicar com o nome para que ex-sista. Reduplicar, fazer-se nomes. E desses nomes forjar um que lhe seja próprio.

Mas a virada esperada em uma análise vai na direção de ouvir do nome não mais o sentido e a significação, mas a diferença absoluta. Contar-se um a partir do n.o.m.e. que, feito letra, pode abrir-se e fazer novos laços.

O próprio manejo que Lacan fará com "Sintoma - Sinn toma - Saint Thomas - Saint homme" (SOLER, 2015) faz aparecer a multiplicidade dos equívocos da escuta da sonoridade, da qual o inconsciente "saber falar" é indissociável. Temos aí um deslizamento livre do sentido.

O nome que lhe é próprio, eis o que Joyce valoriza à custa do pai. Foi a esse nome que ele quis que fosse prestada aquela homenagem que ele mesmo recusou a quem quer que fosse.

Dessa forma, pode-se dizer que o nome próprio faz tudo o que podepara se fazer mais que o $S_{1}$, o significante do mestre, que se dirige rumo ao $S$ que convoquei com o índice pequeno 2 , aquele em torno do qual se acumula o que concerne ao saber.

3 Sobre esse tema, cf. o texto Plus loin que l'inconscient. In: BOUSSEYROUX, M. op. cit. 
[...] O fato que possamos colocar assim um monte de nomes implica apenas o seguinte - fazer entrar o nome próprio no âmbito do nome comum. [...] Vous devez en avoir votre claque. [claque: cansado e palma], e mesmo seu jaclaque, uma vez que lhe acrescentei um han como uma espécie de suspiro de alívio que experimento por ter percorrido hoje esse caminho. Reduzo, assim, meu nome próprio ao nome mais comum (LACAN, 1975-76/2007, pp. 86-87).

O nome próprio não tem qualquer significado aparente a não ser em sua reduplicação nos significados que lhes são associados pelo Outro. Mas Lacan liga seu nome ao som, e com isso traz um novo significado: "Jaclaque han". O "han" que ele cita aparece em outro momento, quando ele escreve o "Il n'y pas" como um som, "hihanpa". Sobre isso, ainda com Soler, temos a indicação preciosa de que "não é o sentido que conta, mas a música, o ritmo, que justamente deixa seu lugar ao enigma da enunciação". Assim, se dos nomes se passa ao nome próprio, Joyce ensina que o nome próprio pode se reduzir ao som: N.O.M.E.

\section{Ecos no Espaço Escola}

Algumas questões do Espaço Escola onde essas articulações foram discutidas: o nome próprio obtura e não diz nada além da novela familiar; ao dizer dele fazemos história, romance. Uma análise passa por isso: quem deu o nome.De onde vem. Mas o fim de uma análise pressupõe ir para além desse romance. Fazer do Nome, Letra. Letra sintoma que reenoda borromeanamente deixando cada registro em seu lugar. A nomeação passa por esse fim da letra sinthoma que se transmite pelo que resta, pelo que fica como marca rasgada - estilo.

Por que esse tema em nosso Espaço Escola? Sofremos com a fixidez criada pelo apego aos nomesenquanto lugares dados pelo outro, confundindo-se assim a dimensão do nome próprio à do nome-sinthoma. Temos os reflexosdessa fixidez que imperam e podem se traduzir como poder. É um ponto frágil, um calcanhar de aquiles dos laços que precisamos manter e cultivar entre os esparsos disparatados.

O nome-sinthoma é justamente esse singular que recolhemose que nos faz esparsos disparatados. Não faz Um. O que se espera de uma Escola é a possibilidade de Uns, em suas soluções únicas, enlaçarem-se nessa diferença. Laços talvez impossíveis, se tentarmos fazê-los homogêneos. A nomeação dada pelo passe dura um tempo limitado, evitando assim uma fixidez.

Quais os efeitos nos laços quando um nome se fixa indefinidamente? Diferente do passe, a designação dos $\mathrm{AMEs}^{4}$ não tem um tempo determinado. Poderia essa

4 Analista Membro de Escola definido na Proposição de 9 de outubro de 1967 como "O AME, ou analista membro de Escola, constituído simplesmente pelo fato de a Escola o reconhecer como 
nomeação ter algum tratamento para não se cristalizar como casta? Manter o gradus $^{5}$ em vez da hierarquia é o desafio de nossa Escola. E talvez, o tratamento joyceano possa ser a dica para tratarmos apenas os sons: A.M.E. e não cristalizar no imperativo: Ame.

\title{
Referências bibliográficas
}

BOUSSEYROUX, M. Lacan le Borroméen. Toulouse: Érès, 2001.

CAMPOS, A. e H. de. Panaroma do Finnegans Wake. 4. ed. São Paulo: Perspectiva, 2001.

JOYCE, J. Finn's Hotel. São Paulo: Companhia das Letras, 2014. Ulysses. Nova Iorque: Dover Publications, 2009

LACAN, J. (1975-76) O seminário, livro 23: o sinthoma. Rio de Janeiro: Jorge Zahar Ed., 2007. . (1964-65) O seminário, livro 12: problemas cruciais para a psicanálise. Inédito.

ROSE, D. i.’.o.l. In: JOYCE, J. Finn's Hotel. São Paulo: Companhia das Letras, 2014. SOLER, C. Lacan, Lecteur de Joyce. Paris: PUF, 2015.

\section{NOMES. NOME. N.O.M.E. Considerações sobre o nome e a transmissão no seminário 0 sinthoma}

\author{
NAMES. NAME. N.A.M.E. \\ Considerations on name and transmission \\ at seminar The sinthome
}

psicanalista que comprovou sua capacidade".

5 Gradus é uma proposta de Lacan para os problemas causados pela hierarquia também em seu texto Proposição de 9 de outubro de 1967. É um conceito ligado à música no que diz respeito ao contraponto. 


\section{resumo}

O presente texto visa apontar os paralelos entre Lacan e James Joyce no que concerne à passagem do processo de nomeação em direção ao nome próprio durante a análise. Partindo dos recortes feitos por Michel Bousseyroux, de um lado; e Colette Soler, de outro, pretende-se indicar o lugar, no "último Lacan", do nome como diferença absoluta, assim como a mudança teórica do autor em relação ao sint(h)oma. Ainda ao fim, serão apresentados alguns ecos dessa teorização sobre a nomeação em meio à dinâmica da nomeação na Escola.

\section{palavras-chave:}

Nomeação; nome próprio; sintoma; sinthoma; Escola.

\section{abstract}

The present text aims to point out the parallels between Lacan and James Joyce in what concerns the passage from the process of nomination to the proper name during psychoanalysis. From the views of Michel Bousseyroux, on one end, and Colette Soler, on the other end, we intend to indicate the place, in the "last Lacan", of the proper name as absolute difference, as well as the theoretical change of the author in regard of the sint(h)ome. At the end, some of the echoes of this theorization about the nomination among the dynamics of the naming at the School will be presented.

\section{keywords:}

Nomination; proper name; symptom; sinthome; School.

\section{Recebido:}

$21 / 05 / 2017$

\section{Aprovado:}

21/06/2017 